BMJ Open Sport \& Exercise Medicine

\section{Investigation of work-life integration on burnout symptoms in women physician runners: a cross-sectional survey study}

Hannah Uhlig-Reche (D) , ${ }^{1}$ Allison R Larson, ${ }^{2}$ Julie K Silver, ${ }^{3,4}$ Adam Tenforde, ${ }^{3,4}$ Alisa McQueen, ${ }^{5}$ Monica Verduzco-Gutierrez ${ }^{6}$

\section{ABSTRACT}

Objective To investigate which factors, from demographics to work-life integration, are associated with burnout symptoms among self-declared active women physicians practising in the USA.

Methods Cross-sectional study of those actively engaged in a social media group for women physician runners. Electronically surveyed using 60 questions covering demographics, compensation, debt and domestic responsibilities with burnout assessed by the Mini-Z Burnout Survey.

Results Of the 369 women meeting inclusion criteria as attending physicians practising in the USA, the majority reported being White $(74.5 \%)$ and at least 6 years out from training (85.9\%). There was a significant association of increased burnout level with working more hours per week and being responsible for a greater percentage of domestic duties ( $p<0.0001$ and $p=0.003$, respectively). Both factors remained significant in a multivariable model $(p<0.0001)$. Conclusion By exploring burnout in the physically active, we are better able to investigate contributors to burnout despite healthy exercise habits. Increased burnout was significantly associated with greater domestic responsibility and hours working. These findings in women physician runners suggest that exercise alone may not control burnout. Poor work-life integration deserves attention as a burnout contributor in women physicians, potentially serving as a target for burnout prevention strategies.

\section{INTRODUCTION}

The prevalence of physician burnout is estimated to be near or exceeding $50 \%$, much greater than the general working population in the USA even after adjusting for work hours and other factors. ${ }^{1-4}$ Defined as a workrelated syndrome consisting of emotional exhaustion, depersonalisation and a reduced sense of personal efficacy or accomplishment, burnout is associated with negative consequences personally and professionally. Patients are at risk of experiencing lower quality care, reduced satisfaction and medical

\section{What are the new findings?}

- Increased burnout was significantly associated with greater domestic responsibility and greater hours working.

- These findings in self-reported physically active women physicians suggest that aerobic exercise alone may not control burnout symptoms.

- Poor work-life integration deserves attention as a burnout contributor in women physicians.

errors while the physician's own mental and physical health and safety are threatened. ${ }^{5}$ Combined, these effects increase healthcare system costs, having adverse impacts on physician productivity and turnover as well as patient access to high quality care. ${ }^{56}$ Burnout affects both men and women, although not necessarily equally. While gender is not a consistently independent predictor of burnout, in some studies, women physicians and physicians-in-training appear to have a higher incidence of burnout symptoms related to depersonalisation and emotional exhaustion compared with their male counterparts which could result in the loss of women from the physician workforce. ${ }^{147}$

With the number of women becoming physicians increasing, burnout in this population warrants further investigation as there is limited existing literature on this. Exercise is a frequently proposed strategy to combat burnout and improve physical and mental health. Studies have shown that physical activity is associated with lower risk of employee and medical student burnout. ${ }^{8-10}$ By exploring burnout in a physically active sample of women physicians, we are better able to investigate contributors to burnout despite healthy exercise habits. Qualitative studies report that attention to work-life integration and self-care behaviours are two of the most commonly employed tactics by 
physicians to address burnout. ${ }^{8}$ As such, we included questions related to these themes in our investigation.

We aimed to investigate which factors, from demographics to finances and work-life integration, were associated with burnout among self-declared active women physicians in the USA. We hypothesised that more demanding occupational hours and poor work-life balance would contribute to burnout. To our knowledge, this is the first study to survey a cohort of self-declared active women physicians and analyse how burnout symptoms are affected by work-life integration.

\section{METHODS}

\section{Objectives}

The primary outcomes were to determine the level of physical activity and prevalence of burnout symptoms in this cohort of women physicians. Secondary outcome was to evaluate associations of demographics and work-life integration with burnout.

\section{Participants}

All group members belonging to an exercise-related social media group for women physicians were invited to participate through an online posting containing the survey hyperlink. To reduce the role of non-response bias, only those members actively engaged in the group, per the metrics provided by the platform's engagement insights, were considered when assessing response rate. Written informed consent was obtained by all participants.

\section{Design}

This cross-sectional study consisted of an electronic survey comprising 60 questions about exercise, demographics, finances and domestic responsibilities. To evaluate work satisfaction and burnout, questions from the American Medical Association's Mini-Z Burnout Survey (MZBS) were included. ${ }^{11}$ Anonymous survey responses were collected over a 3-week period in February and March 2020.

The University of Texas Health Science Center at Houston Institutional Review Board classified this study as exempt.

\section{Analysis}

Surveys included in the analysis belonged to women attending physicians practising in the USA. Missing data were excluded from analysis but accounted for in the summary tables accordingly. One-way analysis of variance was conducted to assess the relationship between the average MZBS Score and demographic factors as well as work-life integration factors, current and maximum compensation, current and maximum educational debt, and current household debt. Linear regression was then conducted using the variables that reached significance in univariate testing. Analysis was conducted in R. ${ }^{12}$

\section{RESULTS}

Of the 1000 actively engaged social media group members, 382 (38.2\%) completed the survey. There were
369 respondents who met inclusion criteria by identifying themselves as attending women physicians practising in the USA, many at least 6 years out from training $(85.9 \%)$, with $74.5 \%$ White, $13.8 \%$ Asian, $6.8 \%$ Hispanic, $2.4 \%$ multiple races and $0.8 \%$ Black. Group demographics are shown in table 1 . Burnout symptoms were reported in $42.1 \%$ of respondents.

\section{Physical activity}

The median amount of time spent exercising per week was $5-6$ hours with the majority $(69 \%)$ being aerobic exercise. One hundred and eighty-one $(60.1 \%)$ of the 301 respondents reporting step counts achieved at least 10000 steps daily.

\section{Work-life integration}

Only $29.5 \%$ of respondents reported having adequate time for work activities while $58.6 \%$ have enough time for their personal and family life. Nearly $41 \%$ reported having reduced their work hours to offset home responsibilities. There was a significant association between higher scores on the MZBS (indicating lower levels of burnout) and agreement that one's work schedule left enough time for personal and family life $(\mathrm{p}<0.0001)$.

Significantly associated with higher levels of burnout were more hours worked per week $(p<0.0001)$ and a greater per cent of domestic duties for which the respondent is responsible $(p=0.003)$. These associations remained significant $(\mathrm{p}<0.0001)$ in the multivariable model (table 2). This relationship is illustrated in figure 1.

\section{DISCUSSION}

\section{Burnout and work-life integration}

In this group of self-declared active women attending physicians in the USA, we found greater degrees of burnout to be significantly associated with performing a higher percentage of domestic duties and working more hours per week. Our findings suggest that these women physicians reporting burnout may be experiencing a work-life imbalance. This is consistent with other studies, one of which found that work-home conflict had a stronger predictive effect for burnout in women physicians. ${ }^{13} 14$ This same study found that work-home facilitation had a significantly protective effect on exhaustion in women. ${ }^{13}$

\section{Strengths and limitations}

A strength of our study is its originality in investigating burnout in the setting of a physically active lifestyle. By assessing commonly employed tactics by physicians to combat burnout such as work-life integration and health behaviours, we can begin to understand their associations with burnout. However, we only assessed exercise and nutrition practices while other self-care behaviours, like meditation and sleep habits, went unmeasured.

We incorporated validated survey questions where possible, such as the MZBS. However, a remaining limitation of this survey-collected data is that it is 
Table 1 Demographic factors

\begin{tabular}{|c|c|}
\hline Category & n (\%) \\
\hline \multicolumn{2}{|l|}{ Race } \\
\hline White & 275 (74.5) \\
\hline Asian & $51(13.8)$ \\
\hline Hispanic & $25(6.8)$ \\
\hline Multiple races & $9(2.4)$ \\
\hline Other & $4(1.1)$ \\
\hline Black or African American & $3(0.8)$ \\
\hline Native Hawaiian or Pacific Islander & $1(0.3)$ \\
\hline American Indian or Alaska Native & $1(0.3)$ \\
\hline \multicolumn{2}{|l|}{ Years out of training } \\
\hline 5 years or less & $48(13.0)$ \\
\hline $6-10$ years & $137(37.1)$ \\
\hline $11-20$ years & $151(40.9)$ \\
\hline More than 20 years & $29(7.9)$ \\
\hline Other & $4(1.1)$ \\
\hline \multicolumn{2}{|l|}{ Primary practice setting } \\
\hline Private practice & $141(38.2)$ \\
\hline Academic & $106(28.7)$ \\
\hline Combination or other & $105(28.5)$ \\
\hline Military or VA & $17(4.6)$ \\
\hline \multicolumn{2}{|l|}{ Clinical work } \\
\hline Outpatient & $181(49.2)$ \\
\hline Inpatient & $62(16.8)$ \\
\hline Equal mix (inpatient/outpatient) & $96(26.1)$ \\
\hline Other & $18(4.9)$ \\
\hline Non-clinical administrative & $6(1.6)$ \\
\hline Research & $5(1.4)$ \\
\hline No response & $1(0.3)$ \\
\hline \multicolumn{2}{|l|}{ Specialty } \\
\hline Obstetrics and Gynaecology & $49(13.3)$ \\
\hline Family Medicine & $43(11.6)$ \\
\hline Internal Medicine Subspecialty & $42(11.4)$ \\
\hline Paediatrics & $39(10.6)$ \\
\hline Paediatric Subspecialty & $35(9.5)$ \\
\hline Internal Medicine & $28(7.6)$ \\
\hline Emergency Medicine & $20(5.4)$ \\
\hline Surgical Subspecialty & $18(4.9)$ \\
\hline Psychiatry & $14(3.8)$ \\
\hline Other & $14(3.8)$ \\
\hline Anaesthesiology & $13(3.5)$ \\
\hline Dermatology & $12(3.3)$ \\
\hline Physical Medicine \& Rehabilitation & $10(2.7)$ \\
\hline Radiology & $8(2.2)$ \\
\hline Neurology & $8(2.2)$ \\
\hline Pathology & $6(1.6)$ \\
\hline Ophthalmology & $3(0.8)$ \\
\hline
\end{tabular}

Continued
Table 1 Continued

\begin{tabular}{|cc}
\hline Category & $\mathbf{n}(\%)$ \\
\hline Allergy and Immunology & $3(0.8)$ \\
\hline General Surgery & $2(0.5)$ \\
\hline Preventive Medicine & $2(0.5)$ \\
\hline Hours worked per week & \\
\hline None & $1(0.3)$ \\
\hline $1-10$ & $4(1.1)$ \\
\hline $11-20$ & $22(6.0)$ \\
\hline $21-30$ & $26(7.0)$ \\
\hline $31-40$ & $85(23.1)$ \\
\hline $41-50$ & $114(31.0)$ \\
\hline $51-60$ & $71(19.3)$ \\
\hline $61-70$ & $31(8.4)$ \\
\hline $71-80$ & $9(2.4)$ \\
\hline$>80$ & $5(1.4)$ \\
\hline No response & $1(0.3)$ \\
\hline Share home with spouse/partner & \\
\hline Yes & $345(93.8)$ \\
\hline No & $19(5.2)$ \\
\hline Other & $4(1.0)$ \\
\hline No response & $1(0.3)$ \\
\hline Number of children & \\
\hline 0 & $0(0)$ \\
\hline 1 & $39(10.6)$ \\
\hline 2 & $208(56.4)$ \\
\hline 3 & $86(23.3)$ \\
\hline 4 & $27(7.3)$ \\
\hline No response & $8(2.2)$ \\
\hline $0 \%-25 \%$ & $1(0.3)$ \\
\hline $51 \%-75 \%$ & $28(7.6)$ \\
\hline
\end{tabular}

VA, Veterans Affairs.

self-reported and thus subject to biases relating to recall and social desirability. ${ }^{15}$ Another important consideration is that of participation, or non-response, bias. Non-respondents may not have participated because they had less time to do so or perhaps they had less motivation to participate because they were experiencing symptoms of burnout. On the other hand, it may be that non-responders are not experiencing symptoms of burnout and thus are less interested in filling out a survey on the topic. These differences in responders and non-responders may have important implications, biasing the results. 
Table 2 Factors associated with burnout from MZBS

\begin{tabular}{|c|c|c|c|}
\hline \multicolumn{2}{|l|}{ Factor } & \multicolumn{2}{|r|}{$P$ value } \\
\hline \multicolumn{4}{|l|}{ Univariate results } \\
\hline \multicolumn{2}{|l|}{ Hours worked per week } & & $<0.00001$ \\
\hline \multicolumn{2}{|c|}{ Per cent of domestic duties } & & 0.0003 \\
\hline Factor & $P$ value & Coefficient & $95 \% \mathrm{Cl}$ \\
\hline \multicolumn{4}{|l|}{ Multivariable model } \\
\hline Intercept & $<0.00001$ & 43.9 & 40.7 to 47.1 \\
\hline $\begin{array}{l}\text { Hours worked per } \\
\text { week }\end{array}$ & $<0.00001$ & -1.39 & -1.79 to -1.00 \\
\hline $\begin{array}{l}\text { Per cent of domestic } \\
\text { duties }\end{array}$ & $<0.00001$ & -1.78 & -2.50 to -1.07 \\
\hline
\end{tabular}

MZBS, Mini-Z Burnout Survey.

\section{Generalisability and future studies}

Our findings are specific to women attending physicians in the USA who participate in mostly aerobic exercise. Applying this investigation to a larger, more heterogeneous sample including diverse fitness practices, men physicians, physicians-in-training and even women in the general population would allow for important comparisons and enhanced generalisability.

\section{CONCLUSION}

These findings in self-reported physically active women physicians suggest that aerobic exercise alone may not control burnout symptoms. Poor work-life integration deserves attention as a burnout contributor in women physicians. Potentially serving as a target for burnout prevention strategies, the improvement of work-life

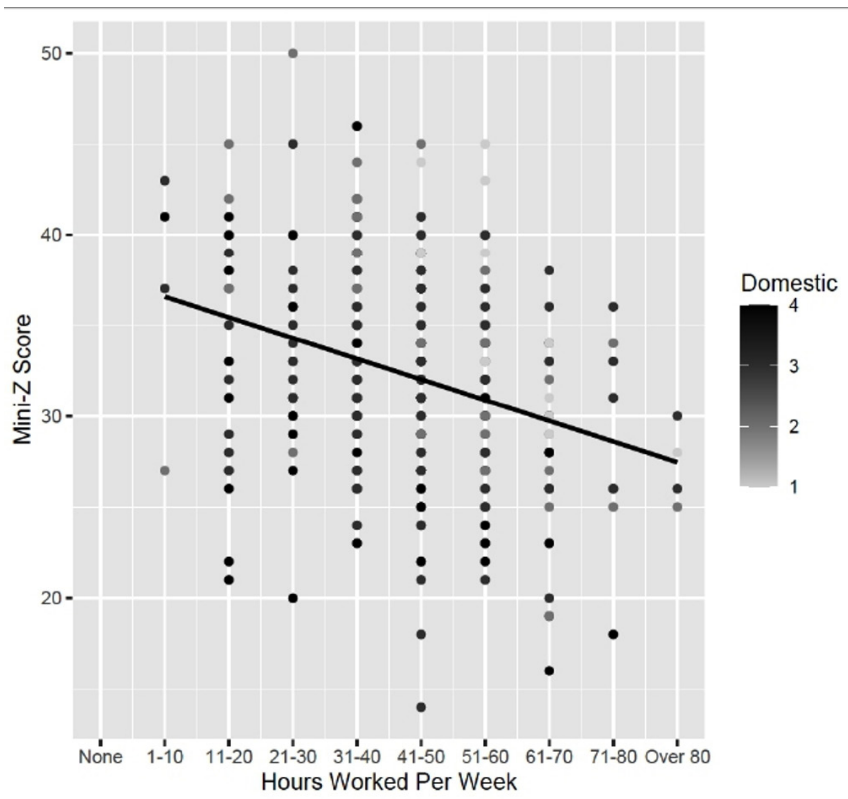

Figure 1 Trend of MZBS Score with weekly hours worked and percentage of domestic responsibility. Mini-Z Scores decreased, indicating a greater degree of burnout, with increasing hours worked and increasing percentage of domestic duties performed. MZBS, Mini-Z Burnout Survey. integration through consideration of aspects like work hours and domestic duties may reduce burnout in women physicians.

Contributors HU-R is a lead author on manuscript, contributed to conceptualisation, investigation, data curation, project administration; ARL contributed to formal analysis, data curation, conceptualisation, investigation, manuscript preparation, review/edit of the manuscript; JKS contributed to conceptualisation, project administration, supervision, review/edit of the manuscript; AT contributed to conceptualisation, review/edit of the manuscript; AM contributed to conceptualisation, review/edit of the manuscript; MV-G contributed to conceptualisation, data collection and curation, project administration, supervision, review/edit of the manuscript.

Funding The authors have not declared a specific grant for this research from any funding agency in the public, commercial or not-for-profit sectors.

Competing interests None declared.

Patient consent for publication Not required.

Provenance and peer review Not commissioned; externally peer reviewed.

Open access This is an open access article distributed in accordance with the Creative Commons Attribution Non Commercial (CC BY-NC 4.0) license, which permits others to distribute, remix, adapt, build upon this work non-commercially, and license their derivative works on different terms, provided the original work is properly cited, appropriate credit is given, any changes made indicated, and the use is non-commercial. See: http://creativecommons.org/licenses/by-nc/4.0/.

\section{ORCID iD}

Hannah Uhlig-Reche http://orcid.org/0000-0002-8417-394X

\section{REFERENCES}

1 West CP, Shanafelt TD, Kolars JC. Quality of life, burnout, educational debt, and medical knowledge among internal medicine residents. JAMA 2011;306:952-60.

2 Shanafelt TD, Boone S, Tan L, et al. Burnout and satisfaction with work-life balance among US physicians relative to the general US population. Arch Intern Med 2012;172:1377-85.

3 Shanafelt TD, Hasan O, Dyrbye LN, et al. Changes in burnout and satisfaction with work-life balance in physicians and the general us working population between 2011 and 2014. Mayo Clin Proc 2015;90:1600-13.

4 Del Carmen MG, Herman J, Rao S, et al. Trends and factors associated with physician burnout at a Multispecialty academic faculty practice organization. JAMA Netw Open 2019;2:e190554.

5 West CP, Dyrbye LN, Shanafelt TD. Physician burnout: contributors, consequences and solutions. J Intern Med 2018;283:516-29.

6 Han S, Shanafelt TD, Sinsky CA, et al. Estimating the attributable cost of physician burnout in the United States. Ann Intern Med 2019;170:784.

7 Dyrbye LN, West CP, Satele D, et al. Burnout among U.S. medical students, residents, and early career physicians relative to the general U.S. population. Acad Med 2014;89:443-51

8 Weiner EL, Swain GR, Wolf B, et al. A qualitative study of physicians own wellness-promotion practices. West J Med 2001;174:19-23.

9 Naczenski LM, Vries JDde, Hooff MLMvan, et al. Systematic review of the association between physical activity and burnout. $J$ Occup Health 2017:59:477-94.

10 Dyrbye LN, Satele D, Shanafelt TD. Healthy exercise habits are associated with lower risk of burnout and higher quality of life among U.S. medical students. Acad Med 2017;92:1006-11.

11 Linzer M, Poplau S, Babbott S, et al. Worklife and wellness in academic general internal medicine: results from a national survey. $J$ Gen Intern Med 2016;31:1004-10.

12 R Core Team. R: a language and environment for statistical computing. Vienna, Austria: R Foundation for Statistical Computing, 2017. https://www.R-project.org/

13 Langballe EM, Innstrand ST, Aasland OG, et al. The predictive value of individual factors, work-related factors, and work-home interaction on burnout in female and male physicians: a longitudinal study. Stress and Health 2011;27:73-87.

14 Dyrbye LN, Varkey P, Boone SL, et al. Physician satisfaction and burnout at different career stages. Mayo Clin Proc 2013;88:1358-67.

15 Althubaiti A. Information bias in health research: definition, pitfalls, and adjustment methods. J Multidiscip Healthc 2016;9:211-7. 